\title{
Nationwide Epidemiologic Survey of Idiopathic Osteonecrosis of the Femoral Head
}

\author{
Wakaba Fukushima MD, PhD, Mikihiro Fujioka MD, PhD, \\ Toshikazu Kubo MD, PhD, Akiko Tamakoshi MD, PhD, \\ Masaki Nagai MD, PhD, MSc, Yoshio Hirota MD, PhD
}

Received: 28 August 2009/ Accepted: 22 February 2010/Published online: 12 March 2010

(C) The Author(s) 2010. This article is published with open access at Springerlink.com

\begin{abstract}
Background Although numerous studies describe the clinical characteristics of idiopathic osteonecrosis of the femoral head $(\mathrm{ONFH})$ in specific study populations, these have not been confirmed in countrywide studies.

Questions/purposes We therefore determined: (1) the annual number of patients seeking medical care and number of patients newly diagnosed; and (2) the distribution of

One or more of the authors (MF, TK, AT, MN, and YH) have received funding from a research grant for the Research on Idiopathic Osteonecrosis of the Femoral Head and the Research on Epidemiology of Intractable Diseases from the Ministry of Health, Labor and Welfare of Japan.

Each author certifies that his or her institution has approved the human protocol for this investigation and that all investigations were conducted in conformity with ethical principles of research.

This work was performed at the Department of Public Health, Osaka City University Faculty of Medicine, Osaka, Japan; Department of Orthopaedics, Graduate School of Medical Science, Kyoto Prefectural University of Medicine, Kyoto, Japan; Department of Preventive Medicine/Biostatistics and Medical Decision Making, Nagoya University Graduate School of Medicine, Nagoya, Japan; and Department of Public Health, Saitama Medical University Faculty of Medicine, Saitama, Japan.
\end{abstract}

W. Fukushima ( $\square)$, Y. Hirota

Department of Public Health, Osaka City University Faculty of Medicine, 1-4-3, Asahi-machi, Abeno-ku, Osaka 545-8585,

Japan

e-mail: wakaba@med.osaka-cu.ac.jp

\section{Fujioka, T. Kubo}

Department of Orthopaedics, Graduate School of Medical

Science, Kyoto Prefectural University of Medicine, Kyoto, Japan

\section{A. Tamakoshi}

Department of Preventive Medicine/Biostatistics and Medical

Decision Making, Nagoya University Graduate School of

Medicine, Nagoya, Japan the age and gender of the patients, potential causative factors, severity of the disease, and operative procedures performed.

Patients and Methods We conducted a nationwide epidemiologic survey in 2005. The survey included all orthopaedic departments in Japan by stratified random sampling according to the number of beds.

Results The number of patients who sought medical care for idiopathic ONFH during 2004 was estimated to be 11,400 (95\% confidence interval, 10,100-12,800). We obtained clinical information from 1502 of these patients. The peak in age distribution occurred in the 40s. Potential causative factors were systemic steroid administration $(51 \%)$ and habitual alcohol use $(31 \%)$. Hip replacement was the most frequently performed procedure $(65 \%)$. Among patients with a history of systemic steroid administration, systemic lupus erythematosus was reported most frequently $(31 \%)$ as the underlying disease. Among patients younger than 40 years, steroid use was the most prominent potential causative factor $(60 \%)$, and hip replacement frequently was performed (45\%). A greater

Present Address:

A. Tamakoshi

Department of Public Health, Aichi Medical University School

of Medicine, Aichi, Japan

M. Nagai

Department of Public Health, Saitama Medical University

Faculty of Medicine, Saitama, Japan 
proportion of patients with no history of steroid or alcohol use was observed among patients 65 years or older (41\%). Conclusions In addition to the disease burden of idiopathic ONFH in Japan, our results confirmed the importance of developing preventive and treatment strategies, especially among the younger population.

Level of Evidence Level IV, prognostic study. See Guidelines for Authors for a complete description of levels of evidence.

\section{Introduction}

ONFH is not a specific disease entity, but rather the final common pathway of a series of conditions leading to impairment of the blood supply to the bone [12, 15]. Numerous studies have revealed the clinical characteristics of idiopathic ONFH in specific study populations, including for pregnant women and patients with rheumatoid arthritis, cancer, or multifocal osteonecrosis [4, 5, 11, 16, 21, 24]. Although these findings document potential causative factors, they have not been confirmed on a countrywide basis. Knowing the frequency of causative factors might be useful for developing preventive measures. Information regarding age distribution would help to establish appropriate treatment strategies for different age groups.

In Japan, the Ministry of Health and Welfare (later, the Ministry of Health, Labor and Welfare) established special measures against so-called "intractable diseases" in 1972. These are defined as a rare disease whose cause has yet to be determined, and for which there still is no established therapy. The program includes promoting research activities, eliminating patients' copayments for medical expenditures, and developing the necessary medical facilities. Under this program, the Research Committee on Idiopathic Avascular Necrosis of the Femoral Head was established in 1975 (after 1982, the Research Committee on Idiopathic Osteonecrosis of the Femoral Head), and nationwide surveys regarding descriptive epidemiology of idiopathic ONFH were conducted four times previously [1, $8,14,18,19]$. However, we believed these findings needed to be updated to reflect the most recent epidemiology of the disease and to confirm previous findings. Thus, a fifth nationwide survey was conducted to clarify the descriptive epidemiology of idiopathic ONFH during 2004; the study was performed cooperatively by the Research Committee on Idiopathic Osteonecrosis of the Femoral Head and the Research Committee on Epidemiology of Intractable Diseases.

We sought to determine: (1) the annual number of patients seeking medical care and number of patients newly diagnosed; and (2) the distribution of the age and gender of the patients, potential causative factors, severity of the disease, and operative procedures performed.

\section{Patients and Methods}

The survey consisted of two queries; the first query estimated the number of patients seeking medical care, and the second query revealed their demographic and clinical features. We performed the survey according to the standardized procedure proposed by the Research Committee on Epidemiology of Intractable Diseases in Japan. The overall method was described previously [17]. The study protocol was approved by the ethics committee of the Graduate School of Medical Science, Kyoto Prefectural University of Medicine as representative, which was the affiliation of the chair of the Research Committee on Idiopathic Osteonecrosis of the Femoral Head in 2005.

We selected the survey targets from all the orthopaedic departments in Japan by stratified random sampling. Two hospital lists were used as the sampling frame: ByoinYohran (primary use), and Iikukikan-Meibo (supplementary use) in Japanese. The lists are widely available in electronic database form and list all the hospitals from north to south in Japan. Stratification was conducted according to the number of hospital beds. Sampling fractions were as follows: general hospitals with 99 or fewer beds (5\%); 100 to 199 beds (10\%); 200 to 299 beds (20\%); 300 to 399 beds (40\%); 400 to 499 beds (80\%); 500 or more beds (100\%); and university hospitals (100\%). For example, regarding a strata of general hospitals with 200 to 299 beds, we randomly selected one orthopaedic department and then selected the next one by a five-department interval, yielding $20 \%$ of the sampling fraction. Forty-six departments that treated a large number of patients with idiopathic ONFH were included by $100 \%$ of sampling fractions.

We began the first query in January 2005. The selected departments for survey targets were asked by mail to report the total number and gender of patients who visited for idiopathic ONFH from January 1 to December 31, 2004. Because we did not collect information other than the total number and gender of patients seen in the department, informed consent was not obtained in the first query. In the first query, 999 departments were sampled as survey targets from 4722 intended departments in Japan, and 577 departments $(58 \%)$ responded. We received reports for 5612 patients with idiopathic ONFH from 327 departments that confirmed they had a patient(s).

The diagnosis of idiopathic ONFH was based on the revised criteria proposed by the Research Committee on Idiopathic Osteonecrosis of the Femoral Head in Japan [22]. Briefly, the criteria comprise five findings: (1) collapse of the femoral head (including crescent sign) without joint 
space narrowing or acetabular abnormality on radiographic images; (2) demarcating sclerosis in the femoral head without joint space narrowing or acetabular abnormality; (3) "cold in hot" on bone scans; (4) low-intensity band on T1-weighted MRI (band-like pattern); and (5) trabecular and marrow necrosis on histology. Idiopathic ONFH was diagnosed if the patient fulfilled two of these five findings and did not have bone tumors or dysplasia. These criteria for diagnosis had $91 \%$ sensitivity and $99 \%$ specificity when histologic diagnosis was used as the gold standard [23]. Although steroids and alcohol are known risk factors, we regarded steroid-induced osteonecrosis and alcoholinduced osteonecrosis as idiopathic ONFH in our survey because their causal mechanisms have not been fully established. A reminder letter was sent in March to departments that had not returned answers.

Accounting for the selection rate and response rate to the survey, we estimated the total number of patients seeking medical care according to the following formula: the estimated total numbers of patients $=$ reported number of patients/(selection rate $\times$ response rate $)=$ reported number of patients/(number of reporting departments/ number of total departments). Additionally, the $95 \%$ confidence interval (CI) was calculated with an assumption of multinominal hypergeometric distribution $[6,7,17]$.

If a department responded that it had a patient(s) in the first query, we sent a second query consisting of structured questionnaire (Appendix 1, English translation of the original form; Appendix 2, in Japanese as the original form) to collect data regarding clinical characteristics of each patient. The questionnaire consisted of the following items: gender, date of birth, date of disease onset, date of disease diagnosis, presence of abnormal findings at the time of diagnosis (hip radiograph, bone scintigram, MRI, bone biopsy), type and stage of disease, potential causative factors (history of systemic steroid administration, history of habitual alcohol drinking, both histories, neither of the histories), underlying illness for which the patient received steroid therapy (in case of a positive history of systemic steroid administration), date of operation, and operative procedure. To reduce the efforts of physicians in each of the departments, and to sample approximately $50 \%$ of total cases, we asked for information for patients born in odd months. In the second query, of the 327 departments that confirmed they had a patient(s) in the first query, 178 departments $(46 \%)$ provided detailed data for 1616 patients. Patients with even-numbered birth months $(\mathrm{n}=31)$, whose first visit to a department was in 2005 $(\mathrm{n}=18)$, who were regarded as having secondary ONFH based on information from the questionnaire $(n=55)$, whose last visit was in 2003 or earlier $(\mathrm{n}=8)$, and for whom there was a later request for exclusion from the participating departments $(\mathrm{n}=2)$, also were excluded.
Consequently, we obtained detailed clinical characteristics for 1502 subjects in the second query.

The working group of the Research Committee on Idiopathic Osteonecrosis of the Femoral Head in Japan proposed the revised classification of disease types and stages in 2002, which has been widely used in Japan since its introduction (Table 1) [22]. Thus, we asked physicians in each of the departments to apply the new classification even if the diagnosis was established earlier than 2002. Briefly, necrotic lesions were classified into four types (A, $\mathrm{B}, \mathrm{C}-1$, and $\mathrm{C}-2$ ) based on their location on T1-weighted MRI or radiographic findings. Staging (1, 2, 3A, 3B, and 4) was defined by AP and lateral views of the femoral head on radiographic images such as demarcating sclerosis, collapse of the femoral head (including crescent sign), or osteoarthritic changes.

In the second query, we also sent reminder letters to departments that had not responded. Additionally, we asked the departments that had responded to confirm or revise fill-ins if the previously returned questionnaire had missing information or lacked consistency. Although detailed information regarding clinical characteristics was collected in the second query, informed consent was not obtained from each patient because anonymity was maintained throughout the second query. Only the department, and not the investigators, could identify the patient if they were asked to confirm or revise fill-ins. If there were missing data even after confirmation or revision, the data were considered as "not filled-in".

\section{Results}

Based on the results from the first query, we estimated that the number of patients who sought medical care during 2004 was 11,400 (95\% CI: $10,100-12,800)$. Of the 1408 patients with available information on the date of diagnosis in the second query, 275 (19.5\%) were newly diagnosed during 2004. If these patients were regarded as new patients, the number of new patients per year was estimated to be $2200(11,400 \times 0.195)$, taking into account the results of the first query.

Among 1502 subjects whose detailed information was obtained in the second query, the peak in age distribution occurred in the 40s (Fig. 1). The gender ratio (male/female) was 1.4 (820/582). In male subjects, the peak in age distribution also occurred in the $40 \mathrm{~s}$, whereas in females, the peak occurred in the 30s. The potential causative factors of ONFH were: systemic steroid administration (steroidinduced) (51\%); habitual alcohol use (alcohol-induced) (31\%); steroid and alcohol use (3\%); and neither steroid nor alcohol use (15\%) (Table 2). The frequency of steroidinduced ONFH was lower among males than females $(34 \%$ 
Table 1. Classification of types and stages of idiopathic ONFH

\begin{tabular}{|c|c|}
\hline \multicolumn{2}{|l|}{ Type* } \\
\hline A & Necrotic lesions occupying the medial one-third or less of the weightbearing portion. \\
\hline B & Necrotic lesions occupying the medial two-thirds or less of the weightbearing portion. \\
\hline $\mathrm{C}-1$ & $\begin{array}{l}\text { Necrotic lesions occupying more than the medial two-thirds of the weightbearing portion but not extending } \\
\text { laterally to the acetabular edge. }\end{array}$ \\
\hline $\mathrm{C}-2$ & $\begin{array}{l}\text { Necrotic lesions occupying more than the medial two-thirds of the weightbearing portion and extending laterally } \\
\text { to the acetabular edge. }\end{array}$ \\
\hline \multicolumn{2}{|c|}{ Stage** } \\
\hline 1 & $\begin{array}{l}\text { The period when there are no specific findings of osteonecrosis on xray images, although specific findings } \\
\text { are observed on MRI, bone scintigram, or histology. }\end{array}$ \\
\hline 2 & The period when demarcating sclerosis is observed without collapse of the femoral head. \\
\hline $3 \mathrm{~A}$ & $\begin{array}{l}\text { The period when collapse of the femoral head, including crescent sign, is observed without joint-space narrowing. } \\
\text { The collapse of the femoral head is less than } 3 \mathrm{~mm} \text {. }\end{array}$ \\
\hline 3B & $\begin{array}{l}\text { The period when collapse of the femoral head, including crescent sign, is observed without joint-space narrowing. } \\
\text { The collapse of the femoral head is } 3 \mathrm{~mm} \text { or greater. }\end{array}$ \\
\hline 4 & The period when osteoarthritic changes are observed. \\
\hline
\end{tabular}

ONFH, osteonecrosis of the femoral head; *based on the central coronal section of the femoral head on T1-weighted images or AP view. The weightbearing portion is defined as the area lateral to the midvertical line of the line through the acetabular edge and the teardrop bottom; **based on AP and lateral views of the femoral head on radiographs. (Published with permission from the Japanese Orthopaedic Association from Sugano N, Atsumi T, Ohzono K, Kubo T, Hotokebuchi T, Takaoka K. The 2001 revised criteria for diagnosis, classification, and staging of idiopathic osteonecrosis of the femoral head. J Orthop Sci. 2002;7:601-605.)

vs $76 \%$ ), whereas the frequency of alcohol-induced ONFH was greater among males than females $(47 \%$ vs $6 \%)$. Stratification by age group $(<40,40-64$, or $\geq 65$ years at diagnosis) indicated a higher frequency of systemic steroid administration in patients younger than 40 years $(60 \%)$. However, patients with no history of steroid or alcohol use were frequently elderly (41\%). Distribution of disease types and stages showed that the most frequent type was $\mathrm{C}-2$ and the most frequent stage was 2 or $3 \mathrm{~A}$ (Table 3 ). There was no remarkable fluctuation after stratification by gender or age group, except for a relatively higher frequency of Stage 4 in the elderly. Of the 1323 joints with operations, hip replacement was the most frequently performed, followed by osteotomy (Table 4). Among patients younger than 40 years, a relatively greater number received an osteotomy (38\%). However, hip replacement also was performed for $45 \%$ of patients in this age group. Systemic lupus erythematosus (SLE) was the most frequent underlying illnesses for the patients with steroid-induced ONFH (Table 5).

\section{Discussion}

We believe it is important to track and update the epidemiology of a disease throughout a country, because such observations may provide information for better understanding of the disease. We therefore determined: (1) the annual number of patients seeking medical care and number of patients newly diagnosed; and (2) the distribution of

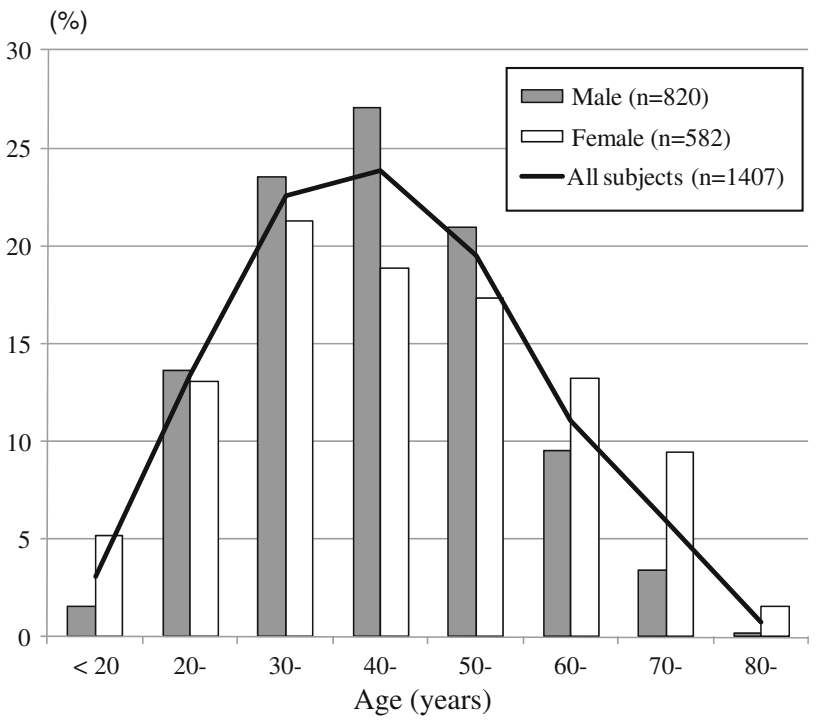

Fig. 1 Age distribution (in years) of the subjects at time of diagnosis is shown. Analysis is based on the subjects whose age at the time of diagnosis was available. There was no available information regarding gender for five subjects.

the age and gender of the patients, potential causative factors, severity of the disease, and operative procedures performed.

Several limitations of this study should be considered before interpreting the results. First, larger teaching institutions represented higher percentages of the survey targets, as these institutions were likely to have more 
Table 2. Distribution of potential causative factors

\begin{tabular}{|c|c|c|c|c|c|c|}
\hline \multirow[t]{2}{*}{ Variables } & \multirow{2}{*}{$\begin{array}{l}\text { All patients } \\
(\mathrm{n}=1502) \\
\mathrm{n}(\%)\end{array}$} & \multicolumn{2}{|c|}{ Stratified by gender* } & \multicolumn{3}{|c|}{ Stratified by age (years) at diagnosis* } \\
\hline & & $\begin{array}{l}\text { Male } \\
(\mathrm{n}=885) \\
\mathrm{n}(\%)\end{array}$ & $\begin{array}{l}\text { Female } \\
(\mathrm{n}=612) \\
\mathrm{n}(\%)\end{array}$ & $\begin{array}{l}<40 \\
(\mathrm{n}=548) \\
\mathrm{n}(\%)\end{array}$ & $\begin{array}{l}40-64 \\
(\mathrm{n}=706) \\
\mathrm{n}(\%)\end{array}$ & $\begin{array}{l}\geq 65 \\
(\mathrm{n}=153) \\
\mathrm{n}(\%)\end{array}$ \\
\hline Systemic steroid administration & $760(51)$ & $295(34)$ & $462(76)$ & $325(60)$ & $340(48)$ & $58(38)$ \\
\hline Habitual alcohol use & $456(31)$ & $415(47)$ & $39(6)$ & $146(27)$ & $253(36)$ & $26(17)$ \\
\hline Both & $47(3)$ & $39(4)$ & $8(1)$ & $16(3)$ & $24(3)$ & $6(4)$ \\
\hline Neither & $225(15)$ & $127(15)$ & $98(16)$ & $59(11)$ & $85(12)$ & $62(41)$ \\
\hline Unknown / Not filled-in & 14 & 9 & 5 & 2 & 4 & 1 \\
\hline
\end{tabular}

Some totals of "\%" do not equal $100 \%$ attributable to rounding; *There was no available information regarding gender for five patients and for age at diagnosis for 95.

Table 3. Distribution of clinical types and stages at diagnosis

\begin{tabular}{|c|c|c|c|c|c|c|}
\hline \multirow[t]{2}{*}{ Variables } & \multirow{2}{*}{$\begin{array}{l}\text { All subjects } \\
(\mathrm{n}=2203) \\
\mathrm{n}(\%)\end{array}$} & \multicolumn{2}{|c|}{ Stratified by gender* } & \multicolumn{3}{|c|}{ Stratified by age (years) at diagnosis* } \\
\hline & & $\begin{array}{l}\text { Male }(\mathrm{n}=1273) \\
\mathrm{n}(\%)\end{array}$ & $\begin{array}{l}\text { Female }(\mathrm{n}=923) \\
\mathrm{n}(\%)\end{array}$ & $\begin{array}{l}<40(\mathrm{n}=856) \\
\mathrm{n}(\%)\end{array}$ & $\begin{array}{l}40-64(\mathrm{n}=1066) \\
\mathrm{n}(\%)\end{array}$ & $\begin{array}{l}\geq 65(\mathrm{n}=195) \\
\mathrm{n}(\%)\end{array}$ \\
\hline Type A & $110(5)$ & $46(4)$ & $63(7)$ & $31(4)$ & $64(6)$ & $14(7)$ \\
\hline $\mathrm{B}$ & $217(10)$ & $98(8)$ & $118(13)$ & $89(10)$ & $105(10)$ & $12(6)$ \\
\hline $\mathrm{C}-1$ & $734(33)$ & $415(33)$ & $317(34)$ & $303(35)$ & $343(32)$ & $60(31)$ \\
\hline $\mathrm{C}-2$ & $1142(52)$ & $714(56)$ & $425(46)$ & $433(51)$ & $554(52)$ & $109(56)$ \\
\hline Stage 1 & $270(12)$ & $137(11)$ & $132(14)$ & $101(12)$ & $148(14)$ & $18(9)$ \\
\hline 2 & $607(28)$ & $338(27)$ & $269(29)$ & $272(32)$ & $272(26)$ & $41(21)$ \\
\hline $3 \mathrm{~A}$ & $554(25)$ & $322(25)$ & $230(25)$ & $234(27)$ & $261(24)$ & $35(18)$ \\
\hline $3 B$ & 408 (19) & $266(21)$ & $142(15)$ & 147 (17) & $211(20)$ & $36(18)$ \\
\hline 4 & $364(17)$ & $210(17)$ & $150(16)$ & $102(12)$ & $174(16)$ & $65(33)$ \\
\hline
\end{tabular}

$\mathrm{n}=$ number of involved joints with description of clinical type and stage in the questionnaire. Some $\%$ totals do not equal $100 \%$ owing to rounding; *There was no available information regarding gender for five patients and age at diagnosis for 60 patients.

Table 4. Characteristics related to operations and type of procedure

\begin{tabular}{|c|c|c|c|c|c|c|}
\hline \multirow[t]{2}{*}{ Variables } & \multirow{2}{*}{$\begin{array}{l}\text { All subjects } \\
(\mathrm{n}=2203) \\
\mathrm{n}(\%)\end{array}$} & \multicolumn{2}{|c|}{ Stratified by gender* } & \multicolumn{3}{|c|}{ Stratified by age (years) at diagnosis* } \\
\hline & & $\begin{array}{l}\text { Male } \\
(\mathrm{n}=1273) \\
\mathrm{n}(\%)\end{array}$ & $\begin{array}{l}\text { Female } \\
(\mathrm{n}=923) \\
\mathrm{n}(\%)\end{array}$ & $\begin{array}{l}<40 \\
(\mathrm{n}=856) \\
\mathrm{n}(\%)\end{array}$ & $\begin{array}{l}40-64 \\
(\mathrm{n}=1066) \\
\mathrm{n}(\%)\end{array}$ & $\begin{array}{l}\geq 65 \\
(\mathrm{n}=195) \\
\mathrm{n}(\%)\end{array}$ \\
\hline \multicolumn{7}{|l|}{ Operation } \\
\hline No & $870(40)$ & $433(34)$ & $435(47)$ & $331(39)$ & $439(41)$ & $75(39)$ \\
\hline Yes & $1323(60)$ & $836(66)$ & $482(53)$ & $522(61)$ & $622(59)$ & $118(61)$ \\
\hline Unknown / not filled-in & 10 & 4 & 6 & 3 & 5 & 2 \\
\hline \multicolumn{7}{|l|}{ Operative procedure (if any) } \\
\hline Osteotomy & $330(25)$ & $233(28)$ & $97(20)$ & $197(38)$ & $121(20)$ & $3(3)$ \\
\hline Bone transplantation & $106(8)$ & $67(8)$ & $39(8)$ & $70(14)$ & $30(5)$ & $0(0)$ \\
\hline Hip replacement & $848(65)$ & $508(62)$ & $335(70)$ & $232(45)$ & $459(74)$ & $115(97)$ \\
\hline Others & $27(2)$ & $18(2)$ & $9(2)$ & $14(3)$ & $9(1)$ & $0(0)$ \\
\hline Unknown / not filled-in & 12 & 10 & 2 & 9 & 3 & 0 \\
\hline
\end{tabular}

$\mathrm{n}=$ number of involved joints with description of clinical type and stage in the questionnaire. Some $\%$ totals do not equal $100 \%$ owing to rounding; *There was no available information regarding gender for five patients and age at diagnosis for 60 patients. 
Table 5. Underlying illness for which patients with steroid-induced ONFH received steroid therapy

\begin{tabular}{lc}
\hline Underlying illness & Number $(\%)$ \\
\hline Systemic lupus erythematosus & $236(31.2)$ \\
Rheumatoid arthritis & $7(0.9)$ \\
Polymyositis/dermatomyositis & $37(4.9)$ \\
Mixed connective tissue disease & $20(2.6)$ \\
Sjöegren syndrome & $8(1.1)$ \\
Other type of collagen disease & $21(2.8)$ \\
Nephrotic syndrome & $48(6.3)$ \\
Nephritis & $19(2.5)$ \\
Renal transplantation & $27(3.6)$ \\
Other organ transplantation & $10(1.3)$ \\
Thrombocytopenic purpura & $33(4.4)$ \\
Aplastic anemia & $13(1.7)$ \\
Hepatitis & $6(0.8)$ \\
Bronchial asthma & $34(4.5)$ \\
Pulseless disease & $1(0.1)$ \\
Skin disease & $19(2.5)$ \\
Eye disease & $32(4.2)$ \\
Other disease & $186(24.6)$ \\
\hline
\end{tabular}

ONFH, osteonecrosis of the femoral head; analysis is based on 760 subjects with history of systemic steroid administration.

experience diagnosing or treating idiopathic ONFH. However, large teaching institutions may be more likely to perform osteotomies, whereas small community hospitals may be more likely to perform hip replacement or provide nonoperative treatment. Our sampling procedure, therefore, may have led to different treatment strategies that did not accurately reflect the entire population in Japan. Second, the validity of the estimated number of patients is important because the response rate was only 58\% in the first query. However, the simple formula used for estimation in this survey would be the most acceptable when investigators have no available information regarding nonresponse facilities [6]. Third, our survey had no definition concerning steroid-induced ONFH or alcohol-induced ONFH, which might have produced considerable misclassification. In previous studies, steroid-induced ONFH was defined by a history of taking $1800 \mathrm{mg}$ prednisolone or an equivalent over 4 weeks, or by a history of continuous corticosteroid medication for at least 2 months $[2,9,10]$. Similarly, some authors classified alcohol-induced ONFH by having a history of greater than $400 \mathrm{~mL}$ or $800 \mathrm{~mL}$ of pure ethanol consumption per week [2, 4, 9-11]. However, even less alcohol consumption or a lower steroid dose would increase the risk of idiopathic ONFH [20], and the causal mechanisms of these factors have not been fully proven. Fourth, the patients included in our survey were prevalent cases (new and old patients), not incident cases (new patients), because the reported subjects were patients seeking medical care during one year previous. Together, with the speculation that patients with collagen disease tend to seek medical treatment without interruption, these factors make it possible to overestimate the frequency of so-called steroid-induced ONFH. Finally, complications of osteonecrosis other than of the femoral head were a concern [4]. We could not assess this possibility because diagnostic imaging for detecting another site of osteonecrosis was not obtained in $42 \%$ of the subjects. However, the prevalence of multifocal osteonecrosis among patients with osteonecrosis was reportedly 3\% [11]. Thus, the impact of this complication on the estimates likely would be small.

The first query of this survey provided an estimation of the annual number of patients seeking medical care $(11,400$; 95\% CI: $10,100-12,800)$ and the number of new patients per year (2200) during 2004. These estimates indicated the current disease burden of idiopathic ONFH in Japan. To the best of our knowledge, no similar investigation has been reported for other countries. Although in one study the number of new cases in the United States has been estimated to be 10,000 to 20,000 per year, this estimate was based on the number of total joint arthroplasties performed annually [13]. A previous nationwide epidemiologic survey in Japan estimated the annual number of patients seeking medical care during 1994 as 7400 (95\% CI: 6700-8200) [1], which suggested a substantial increase in patients of 1.5 times over the previous 10 years. However, we are not certain it is appropriate to conclude the occurrence of idiopathic ONFH has increased, based on the following arguments: (1) in Japan, idiopathic ONFH became a well-known disease after it was designated for financial support in 1992 and the emphasis may have resulted in greater reporting; (2) diagnostic techniques advanced substantially with the introduction of MRI and more cases are likely being diagnosed; and (3) medical staff have became more aware of ONFH development with systemic steroid administration in parallel with better recognition of steroid-induced ONFH. Furthermore, the improvement in the prognosis of underlying illnesses by steroid therapy, ironically, might result in a greater accumulation of patients with steroid-induced ONFH.

The results of the second query revealed the following clinical characteristics of idiopathic ONFH in Japan: (1) the distribution of ages of patients at diagnosis had a peak in the 40s; (2) the gender ratio (male/female) was 1.4; (3) systemic steroid administration was the most frequently reported potential causative factor; (4) Type C-2, Stages 2 and $3 \mathrm{~A}$ were common findings at diagnosis; (5) hip replacement was the most frequently performed procedure, followed by osteotomy; and (6) SLE was the most 
commonly reported underlying disease among patients with a history of systemic steroid administration. The peak in age distribution was almost identical to previous findings $[1,3,15]$. Additionally, our surveys suggested patients younger than 40 years accounted for one-third of all subjects. Among this age group, steroid use was the most prominent causative factor, and hip replacement was still frequently performed. These findings confirm the importance of preventive strategies among the younger population, with focus on the method of steroid administration, especially for SLE. Treatment strategies in relation to joint preservation should be developed as well, because current hip prostheses are unlikely to function sufficiently through the remaining life expectancy of younger patients [15]. A higher proportion of patients with no history of steroid or alcohol use was observed among those 65 years or older. Exploring other causative factors would contribute to understanding the etiology of the disease. Finally, our findings indicated that gender distribution would reflect the potential causative factors of $\mathrm{ONFH}$, to some extent. Together with the fact that there currently is no universal definition of steroid-induced or alcohol-induced ONFH, simple stratification by gender may be an efficient way to handle the variability of the potential causative factors among different study populations.

This survey provides an estimate of the disease burden in Japan. Our results confirmed the importance of developing preventive and treatment strategies, especially among the younger population. Large epidemiologic surveys in other countries would allow comparison with our observations.

Acknowledgments We thank all the medical doctors for participating in the current survey despite their busy schedules in medical practice, education, and research. We also thank Hidemi Hattori (assistant clerk from the Department of Preventive Medicine/Biostatistics and Medical Decision Making, Nagoya University Graduate School of Medicine) for helpful assistance.

Open Access This article is distributed under the terms of the Creative Commons Attribution Noncommercial License which permits any noncommercial use, distribution, and reproduction in any medium, provided the original author(s) and source are credited. 
Appendix 1. The questionnaire for the second query (English translation of the original form in Japanese)

Nationwide Epidemiologic Survey of Idiopathic Osteonecrosis of the Femoral Head

Personal Questionnaire for the Second Query

Health and Labour Sciences Research Grants, Research on Intractable Diseases

The Research Committee on Idiopathic Osteonecrosis of the Femoral Head

The Research Committee on Epidemiology of Intractable Diseases

Address of your facility

Name of your facility :

Name of describer :

Department : 1 . Orthopedic surgery 2.Other (

Date of description (year/month/day) : 2005 /

/

This questionnaire is used only for investigation and private information is strictly secured.

Please be kind to select an appropriate number(s) or fill out.

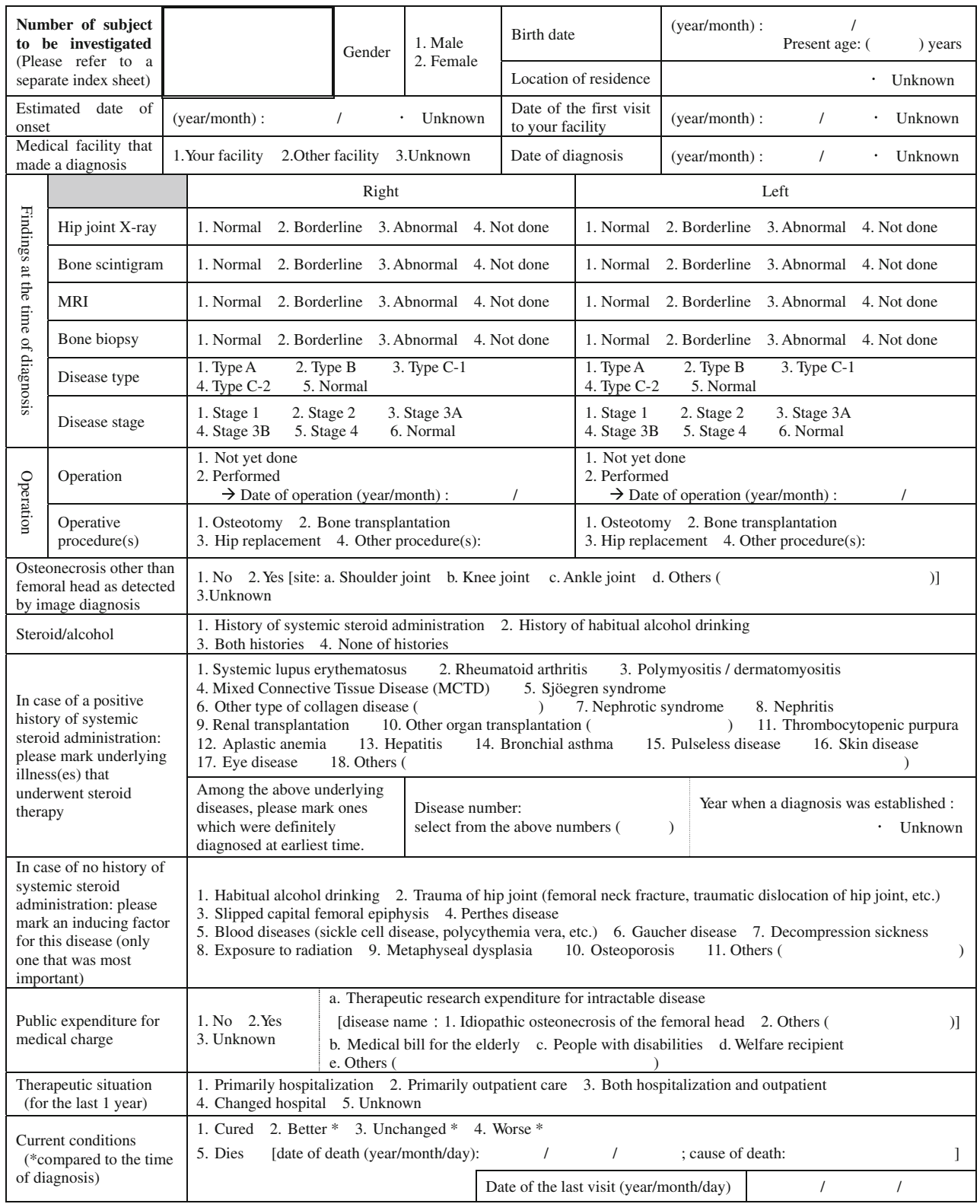


Appendix 2. The questionnaire for the second query (the original form in Japanese)

特発性大腿骨頭壊死症調查個人票

\begin{tabular}{|c|c|c|}
\hline & & $\begin{array}{c}\text { 厚生労働省厚生労動科学研究費補助金 (難治性疾患克服研究事業) } \\
\text { 特発性大腿骨頭壞死症に関する調查研究班 }\end{array}$ \\
\hline 所在地: & & 特定疾患の疫学に関する研究班 \\
\hline 貴施設名: & 記載者氏名 & \\
\hline 担当科名: 1. 整形外科 2.その他（ & ) & 記載年月日 : 2005 年 \\
\hline
\end{tabular}

この票は実態把握のためにのみ使用し、個人の秘密は厳守します。該当する番号を選択、又は御記入下さい。

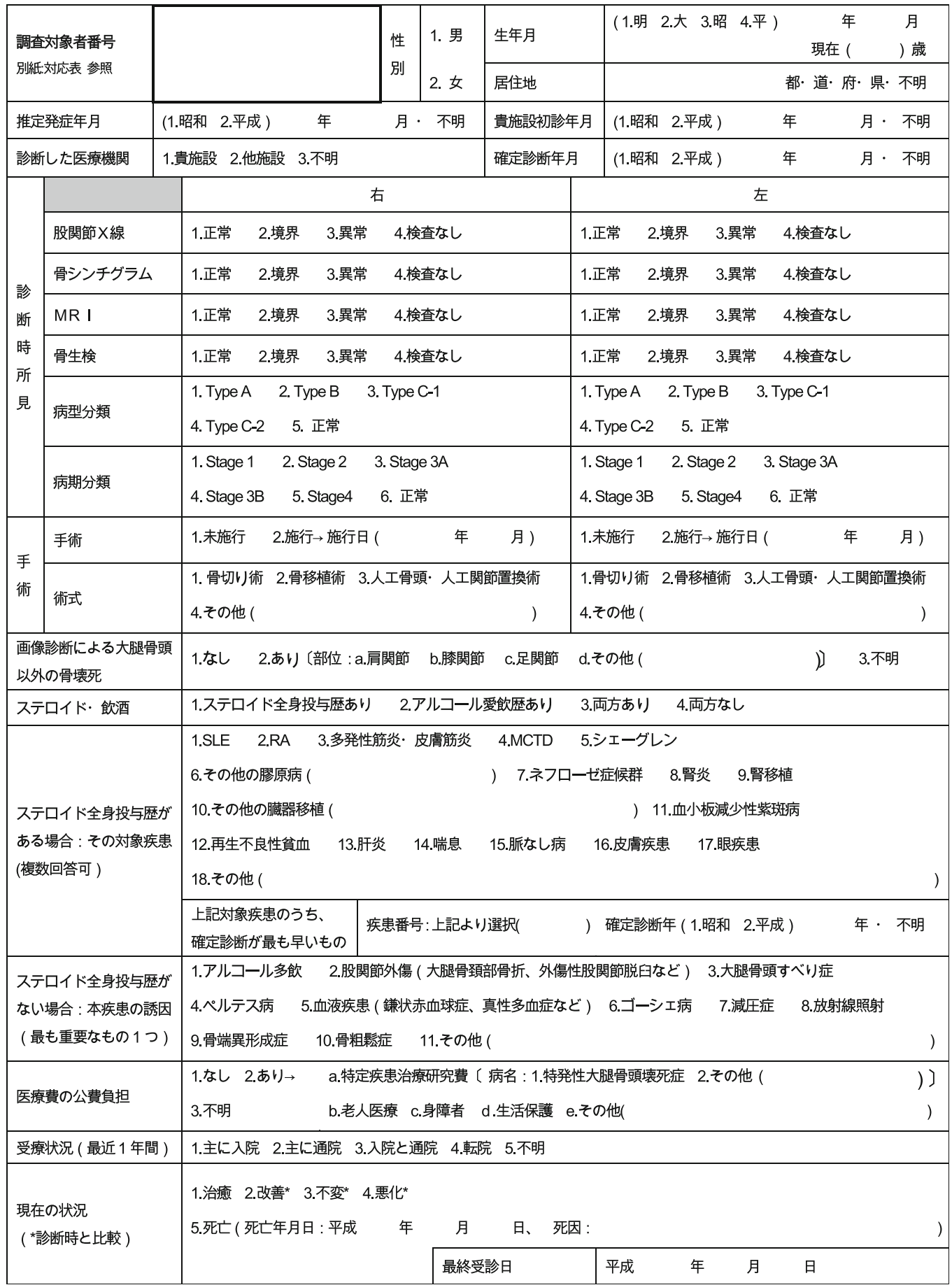




\section{References}

1. Aoki R, Ohno Y, Tamakoshi A, Kawamura T, Wakai K, Senda M, Lin YS, Ninomiya S, Hirota Y, Igarashi Y, Hashimoto S, Aizawa S, Minowa M, Inaba Y. Nationwide epidemiological survey on idiopathic necrosis of the femoral head in Japan. Annual Report of Research Committee on Epidemiology of Intractable Diseases in 1995 [in Japanese]. Tokyo, Japan: Ministry of Health and Welfare of Japan; 1996:67-72.

2. Björkman A, Svensson PJ, Hillarp A, Burtscher IM, Rünow A, Benoni G. Factor V Leiden and prothrombin gene mutation: risk factors for osteonecrosis of the femoral head in adults. Clin Orthop Relat Res. 2004;425:168-172.

3. Castro FP Jr, Harris MB. Differences in age, laterality, and Steinberg stage at initial presentation in patients with steroidinduced, alcohol-induced, and idiopathic femoral head osteonecrosis. J Arthroplasty. 1999;14:672-676.

4. Collaborative Osteonecrosis Group. Symptomatic multifocal osteonecrosis: a multicenter study. Clin Orthop Relat Res 1999;369:312-326.

5. Hanif I, Mahmoud H, Pui CH. Avascular femoral head necrosis in pediatric cancer patients. Med Pediatr Oncol. 1993;21:655660.

6. Hashimoto S, Fukutomi K, Nagai M, Nakamura Y, Yanagawa H, Sasaki R, Ohno Y. A note on methods for estimating the number of patients in the nationwide epidemiological survey on intractable diseases [in Japanese]. Nippon Koshu Eisei Zasshi. 1990;37:768-774.

7. Hashimoto S, Fukutomi K, Nagai M, Nakamura Y, Yanagawa H, Sasaki R, Ohno Y, Kubo N, Aoki K. A method of interval estimation for number of patients in the nationwide epidemiological survey on intractable diseases [in Japanese]. Nippon Koshu Eisei Zasshi. 1991;38:880-883.

8. Hirota Y, Hotokebuchi T, Sugioka Y. Idiopathic osteonecrosis of the femoral head; nationwide epidemiologic studies in Japan. In: Urbaniak JR, Jones JP Jr, eds. Osteonecrosis-Etiology, Diagnosis and Treatment. Rosemont, IL: American Academy of Orthopaedic Surgeons; 1997:51-58.

9. Hong JM, Kim TH, Chae SC, Koo KH, Lee YJ, Park EK, Choi JY, Ryoo HM, Kim SY. Association study of hypoxia inducible factor 1alpha (HIF1alpha) with osteonecrosis of femoral head in a Korean population. Osteoarthritis Cartilage. 2007;15:688694.

10. Koo KH, Lee JS, Lee YJ, Kim KJ, Yoo JJ, Kim HJ. Endothelial nitric oxide synthase gene polymorphisms in patients with nontraumatic femoral head osteonecrosis. J Orthop Res. 2006;24: $1722-1728$.
11. LaPorte DM, Mont MA, Mohan V, Jones LC, Hungerford DS. Multifocal osteonecrosis. J Rheumatol. 1998;25:1968-1974.

12. Lavernia CJ, Sierra RJ, Grieco FR. Osteonecrosis of the femoral head. J Am Acad Orthop Surg. 1999;7:250-261.

13. Mankin HJ. Nontraumatic necrosis of bone (osteonecrosis). N Engl J Med. 1992;326:1473-1479.

14. Masuda T. Epidemiologic survey on idiopathic osteonecrosis of the femoral head. Annual Report of Research Committee on Idiopathic Osteonecrosis of the Femoral Head in 1983 [in Japanese]. Tokyo, Japan: Ministry of Health and Welfare of Japan; 1984:63-65.

15. Mont MA, Hungerford DS. Non-traumatic avascular necrosis of the femoral head. J Bone Joint Surg Am. 1995;77:459-474.

16. Montella BJ, Nunley JA, Urbaniak JR. Osteonecrosis of the femoral head associated with pregnancy: a preliminary report. J Bone Joint Surg Am. 1999;81:790-798.

17. Nakamura Y, Matsumoto T, Tamakoshi A, Kawamura T, Seino Y, Kasuga M, Yanagawa H, Ohno Y. Prevalence of idiopathic hypoparathyroidism and pseudohypoparathyroidism in Japan. J Epidemiol. 2000;10:29-33.

18. Nimomiya S, Ono K. Epidemiologic survey on idiopathic osteonecrosis of the femoral head in 1987. Annual Report of Research Committee on Idiopathic Osteonecrosis of the Femoral Head in 1988 [in Japanese]. Tokyo, Japan: Ministry of Health and Welfare of Japan; 1989:269-271.

19. Ninomiya S, Tagawa H, Miyanaga Y, Okutsu I. Nationwide epidemiologic survey on idiopathic avascular necrosis of the femoral head. Annual Report of Research Committee on Idiopathic Avascular Necrosis of the Femoral Head in 1977 [in Japanese]. Tokyo, Japan: Ministry of Health and Welfare of Japan; 1978:19-25.

20. Rombouts JJ. Etiological factors of avascular necrosis of the femoral head: twenty years later. Acta Orthop Belg. 1999; 65(suppl 1):3-4.

21. Steib-Furno S, Luc M, Pham T, Armingeat T, Porcu G, Gamerre M, Chagnaud C, Lafforgue P. Pregnancy-related hip diseases: incidence and diagnoses. Joint Bone Spine. 2007;74:373-378.

22. Sugano N, Atsumi T, Ohzono K, Kubo T, Hotokebuchi T, Takaoka K. The 2001 revised criteria for diagnosis, classification, and staging of idiopathic osteonecrosis of the femoral head. J Orthop Sci. 2002;7:601-605.

23. Sugano N, Kubo T, Takaoka K, Ohzono K, Hotokebuchi T, Matsumoto T, Igarashi H, Ninomiya S. Diagnostic criteria for non-traumatic osteonecrosis of the femoral head: a multicentre study. J Bone Joint Surg Br. 1999;81:590-595.

24. Zabinski SJ, Sculco TP, Dicarlo EF, Rivelis M. Osteonecrosis in the rheumatoid femoral head. J Rheumatol. 1998;25:1674-1680. 